SPECIES RESILIENCE

\section{Shelving old habits}

PLoS ONE 9, e85285 (2014)

Although Emperor Penguins are abundant, their reliance on sea ice for breeding makes them potentially highly vulnerable to climate change. Estimates of projected changes in sea ice around the Antarctic coastline suggest that populations could be halved by the 2050 s.

Populations of these penguins are remote and frequently inaccessible, but they are amenable to satellite monitoring. Using this approach, Peter Fretwell, from the British Antarctic Survey, and co-workers have identified a number of colonies using glacial ice shelves, rather than sea ice, as their breeding sites. Two of these colonies were particularly interesting because they were found to switch between breeding sites, sometimes occupying the ice shelf and sometimes the sea ice. The choice, at least for the largest colony, seemed to reflect the timing of sea ice formation with relocation to the ice shelf occurring in years when sea ice formation was late. The authors note that the discovery of this new breeding behaviour at climatically marginal sites could mitigate some of the consequences of sea ice loss for these enigmatic birds.

\section{ENERGY}

\section{European biorefineries}

Environ. Sci. Policy http://doi.org/qvq (2013)

Investments in biorefineries for the production of transport fuel and other chemical products are being encouraged to meet emissions reduction targets. However, little is known about the socio-economic implications of the land use and feedstock processing chains associated with these refineries.

Patricia Thornley, of Aston University, UK, and colleagues analysed European biorefinery systems using indigenous wheat straw and softwood to estimate the likely trade, employment and land-use impacts in selected countries. They found that, given feedstock trade potential, it may not be possible to create more than 100 European facilities. New economically viable biorefineries could be a significant source of employment, with job creation per unit of feedstock higher than for biomass power plants. But biorefineries may only contribute $1 \%$ of gross domestic product in European Union member states. An increasing number of straw-based facilities could expand the market for straw as a feedstock, with potential diversion of straw from soil incorporation and consequently additional greenhouse gas emissions to keep nutrient levels in agricultural soils.

\section{POLICY}

\section{Efficiency standards}

J. Environ. Econ. Manag. http://doi.org/qvr (2013)

Energy efficiency standards are policy tools to address market failures like undesired carbon emissions from energy use and consumers' misperceptions about energy savings from cost-effective technologies leading to low adoption levels. However, the economic and environmental effectiveness of these instruments is still debated.

Ian W. H. Parry, of the International Monetary Fund, and colleagues used an analytical model to analyse efficiency standards and pricing policies for reducing
ECOLOGICAL TRANSITIONS

\section{Simulating ecosystem shifts}

Environ. Res. Lett. 8, 044018 (2013)

Climate change could potentially lead to fundamental ecosystem transitions. However, it remains difficult to move beyond this broad concept and begin to answer specific questions, like how much climate change can be tolerated before complex ecological systems start to shift.

Mirroring developments in atmospheric science, progress in understanding the risks of ecosystem shifts under climate change and associated uncertainties, is likely to come from multi-model and multi-scenario ensemble assessment. This is a challenging task, but Lila Warszawski, from the Potsdam Institute for Climate Impact Research, and co-workers have taken an important step in this direction. Based on simulations from seven global vegetation models and a range of future climate scenarios, they use aggregate changes in ecosystems' biogeochemical state (for example, net primary productivity and vegetation carbon) as a proxy for the risk of ecosystem shifts under different levels of global warming.

Their results suggest that $5-19 \%$ of naturally vegetated land is at risk of severe ecosystem change under $2^{\circ} \mathrm{C}$ of global warming, but with limited consensus across the models as to which regions face the highest risks.

petrol and electricity use, and for mitigating carbon emissions in the US. In the case of fuel, they found that taxes alone are generally more efficient than a combination of taxes and standards. For electricity use, combining taxes and standards makes only a slight improvement. Finally, in the absence of misperceptions over energy savings, a combination of energy and emissions standards can cost three times more than carbon pricing. With large misperceptions, combining carbon pricing with fuel or electricity taxes is better than combining it with energy efficiency standards.

SEA-LEVEL RISE

\section{Amplified cycle}

Geophys. Res. Lett. http://doi.org/atd (2014)

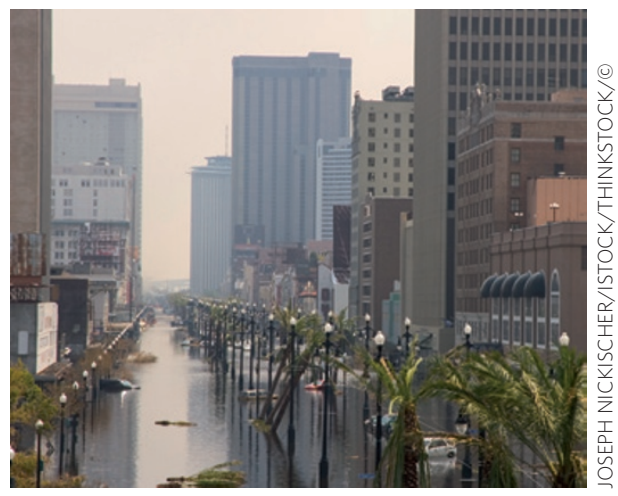

Sea level has a seasonal cycle, with the amplitude and timing controlled by a number of factors, such as temperature, salinity and wind. The coastal areas of the Gulf of Mexico are at risk from changes to this cycle because there are many low lying regions.

Thomas Wahl, of the University of South Florida, and co-workers use tide gauge data from the US Gulf Coast to investigate decadal changes in seasonal sea level. The annual sea-level cycle is found to have been amplified by up to $30 \%$ since the 1990 s, with eastern Gulf winter sea levels lower and summer levels higher.

In combination with atmospheric data, sea surface temperature and reconstructions, the team create regression models to explore the drivers of observed decadal variability and recent increases. Changes in atmospheric temperature, tending towards more extreme seasons, are shown to explain most of the sea level increase, which has doubled the risk of hurricane flooding for the eastern and northeastern coastlines.

Written by Alastair Brown, Monica Contestabile and Bronwyn Wake. 